\title{
Chapter 4 \\ The Emergence of Technoscientific Fields and the New Political Sociology of Science
}

\author{
Benjamin Raimbault and Pierre-Benoît Joly
}

\subsection{Introduction}

Although use of the term synthetic biology in the scientific literature dates back to the early twentieth century, contemporary synthetic biology started to bloom around the turn of the new millennium and has been presented as novel-perhaps even revolutionary-and 'cool'. Like most emerging fields, synthetic biology has been defined in numerous different ways by members of a self-selected community in the making. The European Commission (EC) opinion on synthetic biology (2014) identifies 35 published definitions and proposes the following: 'SynBio is the application of science, technology and engineering to facilitate and accelerate the design, manufacture and/or modification of genetic materials in living organisms (p5)'. Synthetic biologists suggest that compared to modern biotechnology (e.g. genetic engineering, genomics, high throughput biology, etc.), the epistemic novelty of synthetic biology (Synbio) lies in the systematic use of engineering approaches to intentionally design artificial organisms.

Among the numerous analyses of Synbio, many focus on the role of actors active in the field's construction. The American civil engineer Drew Endy, who originally summarised Synbio as aimed 'to make biology easier to engineer', is often invoked as the heroic entrepreneur who played a key role in the emergence of this new field (Campos 2013). Social scientists have investigated the emergence of Synbio using mostly ethnographic approaches or in collaborations with Synbio scientists. The field of enquiry then becomes the (American) lab and/or boundary spaces such as the International Genetically Engineered Machine (iGEM) competition, a very popular

\footnotetext{
B. Raimbault $(\bowtie) \cdot$ P.-B. Joly

Laboratoire Interdisciplinaire Sciences Innovations Sociétés (LISIS), CNRS, INRAE,

Université Gustave Eiffel, Marne-la-Vallée, France

e-mail: raimbault.benjamin6@gmail.com; joly@inra-ifris.org 
student contest in Synbio, or governance institutions. As enlightening and rich as those works are, few-with the notable exceptions of Bensaude-Vincent (2013) and Molyneux-Hodgson and Meyer (2009) —offer a more generic perspective of the emergent scientific knowledge at the scale of the discipline or specialty.

In line with the new political sociology of science (NPSS) and the call for renewed attention to institutional factors and asymmetries of power (Frickel and Moore 2006), this chapter proposes to analyse the emergence of Synbio as a technoscientific field (TSF). The phrase TSF summarises the two theoretical influences we draw on in this work. First, the term techno-scientific refers to the constructivist approach in science and technology studies (STS) which analyses scientific production as a coproduction process-social and epistemic, cognitive and material, cultural and natural, human and non-human. STS covers a heterogeneous set of theories, but we focus mainly on actor-network theory (ANT). Second, our reference to field is grounded in the sociological theory developed by Pierre Bourdieu (1975). We draw also on recent developments by Neil Fligstein and Doug McAdam who proposed a theory of strategic action fields (SAF). They define an SAF as a "constructed mesolevel social order in which actors interact with one another on the basis of shared understandings about the purposes of the field, relationships to others in the field (including who has power and why), and the rules governing legitimate action in the field' (Fligstein and McAdam 2012, p. 9). Thus, field theory allows analysis of emergence from the perspective not only of the production of knowledge and artefacts but also of the emergence of a social order that involves a common understanding of what is at stake, the power relations and hierarchies, and the rules that govern interactions.

Our objective is both methodological and theoretical. The emergence of scientific disciplines has long been a major issue for sociology and the philosophy of science. ${ }^{1}$ However, interest in it faded after the 1980s for two reasons. On the one hand, scholars for whom the discipline constitutes a key form of the organisation of scientific production generally consider disciplines to be stable organisational and cognitive entities. They are not much interested in studying their emergence. On the other hand, STS scholars generally do not consider disciplines to be relevant entities: 'Anti-disciplinary partisans' (the expression coined by Marcovitch and Shinn (2011)) see a radical discontinuity between disciplines from the present and those from the past and, at times, consider that we are living in a post-disciplinary world (Gibbons et al. 1994; Nowotny et al. 2001).

We suggest that it is time to re-engage with the emergence of scientific fields in a new way. First, a number of fields have emerged since the 1970s as technoscientific fields as they are characterised by a strong coupling of basic knowledge and technological tools. Biotechnology and nanotechnology are emblematic examples. However, scholars interested in technoscience (Latour, Hottois, etc.) generally side with the anti-disciplinary camp and hence do not focus on the emergence of new

\footnotetext{
${ }^{1}$ See, inter alia, Ben-David and Collins 1966; Kuhn 1962; Lemaine et al. 2012; Mullins 1972.
} 
fields ${ }^{2}$ ). We suggest that the emergence of technoscientific fields is conditioned by both internal (e.g. scientific credibility) and external (e.g. societal relevance) dynamics. In contrast to scholars such as Marcovich and Shinn (2011) who take the rise of a 'new disciplinarity' seriously but focus exclusively on internal dynamics, we consider that this hybrid nature must be integrated upfront in the analytical framework. Second, the availability of data and new algorithms allows the design and implementation of innovative approaches that match quantitative and qualitative methods. In addition, the new political sociology of science perspective leads to serious consideration of the role of pre-existing entities (institutions, values, norms, infrastructures) in the constitution of scientific fields.

We begin by describing our approach to the emergence of a technoscientific field and then outline our original digital inquiry methodology. The final section of the chapter presents the results of our analysis of Synbio to illustrate the fecundity of new scientometric methods applied within an analytical frame which draws on both STS and field theory.

\subsection{Theoretical Framework-The Emergence of Technoscientific Fields Revisited}

In their review published in the 2016 edition of the Handbook of Science and Technology Studies, Ed Hackett and his colleagues point to the different reasons which might explain the emergence of a new scientific field: coherent networks that arise around potentially generative questions or phenomena; new research instrumentation which allows the knowledge field to be extended; original research ideas that capture the attention of influential groups; the promise of new uses for new scientific knowledge; and, of course, the cumulative effect of these factors which often condition the institutionalisation of a new field (Hackett et al. 2016, p. 740).

The first of these reasons has been explored in depth in the literature. Thomas Kuhn's book The Structure of Scientific Revolution points to the ways that social processes and events shape the internal content of intellectual and scientific inquiry (Kuhn 1962). Nicholas Mullins adopts a similar perspective in his paper on the origins of molecular biology. Mullins presents a model of emergence based on socio-cognitive dynamics (Mullins 1972). The process of emergence begins with identification by a group of researchers of a 'central intellectual problem' and ends with the completion of the 'specialty' as 'an institutionalised cluster which has developed regular processes for training and recruitment into roles which are institutionally defined as belonging to that specialty. Members are aware of each other's work, although not necessarily deeply involved in communications with one another' (Mullins 1972, p. 74). The role of a small coherent network of scientists has also been studied by several different scholars, including Diana Crane who

\footnotetext{
${ }^{2}$ With Bensaude-Vincent (2013) again being the exception.
} 
systematically analyses the communication of scientific knowledge in two scientific fields (maths, rural sociology). She identifies the crucial role of a small set of scientists - the 'invisible college'-who monopolise scientific recognition and play a key role in establishing cognitive and social norms (Crane 1972). In contrast, Harry Collins (1974) developed a critique that would become influential in STS. His main argument was that the interactions within scientific communities are not a matter of exchanges of codified information but rather exchanges of tacit information and practices that are not captured well using scientometric approaches. However, like Crane, Collins considers that a subset of scientists play a key role. He proposed the concept of 'core-set'-defined as scientists 'who are actively involved in experimentation or observation, or making contributions to the theory of the phenomenon, or of the experiment, such that they have an effect on the outcome of the controversy' (Collins 1981, p. 8). More recently, Frickel and Gross (2005) highlighted the key role played by actors with high scientific capital together with younger scholars whose intellectual genealogies connect them to high-status networks. Their argument is close to Fligstein and McAdam (2012) who suggest that field changes (including the emergence process) are triggered by an alliance between some incumbents and some challengers.

Drawing on these contributions, we also suggest that the dynamics of the co-evolution of a coherent network of key actors and a set of central research questions is the main driver of the emergence process. However, our approach focusses on two key elements. First, we assume that the emergence of a technoscientific field is a multi-scalar dynamic in which the micro, meso, and macro levels are intertwined, while simultaneously conserving their specificity. This is a major difference to approaches based on ANT. ${ }^{3}$ Second, we suggest that interactions between the internal dynamics of the emergent field and its broader environment (including the non-scientific environment) constitute a key component of the emergence process. This is a major difference with a Bourdieusian analysis of scientific field which praises the autonomy of the field as guaranteeing the purity of science.

\subsubsection{Emergence as a Multi-Scalar Process}

Whereas networks are characterised by their fluidity, multi-membership, and lack of clear frontiers, action fields are bounded, and the actors are strongly interdependent and share a common understanding of the stakes and rules of the field. Local interactions and network dynamics (intensification of communication, extension of interactions) are key components but are both constrained and constitutive of the

\footnotetext{
${ }^{3}$ See the recent paper by Bruno Latour and colleagues (2013) who develop digital approaches to analyse technoscientific dynamics. In line with ANT, they use numerical profile databases to test the Tardian hypothesis of a monadic world that dissolves the micro and macro scales.
} 
meso-level order. ${ }^{4}$ This focus on the meso-level order properties that characterise SAF is instrumental.

In Bourdieusian field theory, change is the result of struggles between groups of actors whose positions (e.g. dominators vs dominated) depend on the distribution of capital. The capital of the scientific field is constituted mainly by the recognition of peers-competitors (Bourdieu 1975). Also, Fligstein and McAdam (2012) point to the role of internal struggles and suggest more specifically that field emergence generally requires an alliance among the challengers-who have specific social skills related to the settlement of a new field - and the incumbents. They insist also on the influence of the broader environment. Fields do not exist in a vacuum, and relations with other fields play a key role in their dynamics. Following Fligstein and McAdam, we suggest that two types of relations have a major influence on scientific fields. On the one hand, fields have a Russian doll-like structure: fields are embedded within other fields, with any number of smaller fields nested inside the larger ones. A specific illustration might be: science/biology / plant biology /plant genetics /corn genetics (etc.). Smaller fields have partial autonomy; the repertoire of rules in the fields in which they are embedded in is both a constraint and a result of the combined actions of the actors involved. The emergence of a new field is accompanied by a change to the rules, shared meanings, and collective identity. On the other hand, scientific fields have some relations to non-scientific fields. For instance, in line with Fligstein and McAdam (2012), Elisabeth Popp Berman (2014) shows that the marketisation of US academic science is related to the combined role of a changing environment and bottom-up internal strategies. We expand on this below.

Fligstein and McAdam (2012, p. 89) characterise emerging fields as arenas where agreement over the basic conditions of the SAF have yet to emerge. ${ }^{5}$ They identify four elements that shape the process of field formation: mobilisation (in our case, identification of an original central intellectual problem which steers the actors to engage in new directions); social skills that favour the stabilisation of a new order; state intervention (for instance, funding of new specific research programmes); and the creation of new organisations (in our case scientific associations, journals, annual conferences, etc.)

Considering the specialised literature on the emergence of a scientific field as well as Fligstein and McAdam (2012), we assume that a small collective of scientists plays a core visioning role. We call this collective the core-group in order to insist on (1) the central (core) position of scientists belonging to it and (2) the interactions and alliances among the members of this group. Social skills of members of this group are related first to the identification of the new research questions which constitute

\footnotetext{
${ }^{4}$ This representation of multi-scalar dynamics draws on Anthony Giddens's (1984) structuration theory and his notion of duality of the structural.

${ }^{5}$ The four basic conditions are: (1) a shared understanding of what is going on in the field, i.e. what is at stake; (2) a set of relatively fixed actors in the field whose roles and comparative status/power are consensually defined by others in the SAF; (3) a set of shared understandings about the nature of the 'rules' that will govern interaction in the field; (4) a broad interpretive frame that individual and collective strategic actors introduce to make sense of what others within the SAF are doing.
} 
existential cement. Social skills are needed also for creating the new organisations that support the existence of the field.

Members of the emerging field come from neighbouring fields, and the process of emergence is conditioned by their ability to recruit new members while reinforcing the boundaries of the field. Here, following Thomas Gieryn (1995), we consider emergence as a boundary-work process based on stabilisation of a new set of rules which are both epistemic and social. Epistemic rules bring together the establishment of an epistemic culture, notably a set of research practices and standards of proofs and a common research agenda (Knorr-Cetina 1999), whereas social rules refer to common values and norms that define, for example, relations with industry, relations with other disciplines, intellectual property rights, etc. We concur with Marcovich and Shinn's (2011) observation that in the case of nanoscience, the scientists involved remain strongly grounded in their referent disciplines. The process of emergence of a scientific field proceeds through progressive specialisation of a community of scientists. The process involves participation of a fuzzy and evolving population. As Frickel (2004) mentions, the boundaries of an emerging field are porous. In the early phases of the emergence process, actors may be experimenting with and testing new research ideas and new social rules while remaining strongly attached to their referent disciplines. In these early phases, outcomes are uncertain and depend on the ability of the emergent field to demonstrate its credibility and legitimacy.

How do the members of this core-group identify one another? How does the external analyst identify the group? We assume scientific publications-because of their role in the attribution of priority rights and in the allocation of scientific capital-may facilitate the external analyst's identification of the core-group. A given scientist will signal his or her interest in the Synbio field through the use of specific terms in the most visible parts of the paper and by quoting members of the core-group. This process of literary inscription (Latour and Woolgar 1986) provides traces which the analyst can use to analyse the emergence process.

In contrast to the literature on the emergence of a scientific field which insists on a shared understanding of the stakes related to the new field, we argue that cognitive heterogeneity is constitutive of the process of emergence of a technoscientific field. ${ }^{6}$ Our argument is based on two characteristics of technoscientific fields (Joly 2013). First, the engagement of actors in a new emerging field is motivated by strong expectations and the promise of success, which means that it has to build on a breakthrough — a radical novelty — while also being scientific credible. Second, in the process of emergence of a technoscientific field it is necessary to enrol diverse audiences beyond scientists, such as venture capitalists, big companies, regulators, policy makers, and the wider public. Heterogeneity is crucial for meeting the diverse and somewhat contradictory constraints.

\footnotetext{
${ }^{6}$ This does not mean that heterogeneity is associated only with emergence. As one reviewer pointed out, heterogeneity can also signal fragmentation or dissolution. However, the theoretical point here is that heterogeneity plays an active role in the process of emergence for the reasons discussed.
} 


\subsubsection{Strategic Control of External Relations}

In the case of the emergence of scientific fields, the process is fostered by perceived scientific opportunities related to a shift in the research frontier. Hackett et al. (2016) suggest that other complementary reasons may explain the emergence of a new field, and their combination is generally necessary for the institutionalisation of a new field. Here we want to focus on a factor that is essential to a technoscientific field: the need to address societal problems. Following this, we assume that the work performed at the boundary of the field is instrumental to the emergence of a new field. A new field does not emerge only as a result of interactions within the scientific field. As already mentioned, control of external resources (including state intervention) is necessary for this process to occur. This recalls Latour and Woolgar's (1986) proposition in their Laboratory Life of an extended credibility cycle which takes into account the transformation of external resources into scientific capital. Following this intuition, research on the science/industry links shows that, depending on their position in the scientific field, laboratories may exploit the links with industry (Joly and Mangematin 1996). It has been shown also that these links induce a higher propensity for explorative research, whereas peer regulation reinforces normal science (Evans 2010). More generally, these observations are related to the notion of the strength of weak ties: control of external links constitutes a strategic resource (Granovetter 1973).

In this respect, the idea of an extended credibility cycle is important. Therefore, within the perspective of emergence, it is necessary to analyse how the strategies of boundary spanners secure access to critical resources.

Three propositions to describe and analyse the emergence of a TSF can be made. They are related to the three arguments as outlined: (1) the role of heterogeneity. Our first proposition claims that heterogeneity (of disciplines, research questions, visions, and social norms) plays a key role in the emergence phase of a new technoscientific field.; (2) the way actors' positions (or hierarchies) can influence the process. This leads us to a second proposition where alliances between different types of scientific entrepreneurs (incumbents and challengers) are instrumental to the process of emergence; and finally (3) the strategic interactions between the studied field and other fields (autonomy) connected to the last proposition highlighting the importance of strategies for the control of external resources in the process of emergence. 


\subsection{Use of Advanced Scientometrics and Qualitative Methods}

The divide between quantitative (mainly scientometric) and qualitative (mainly ethnographic) approaches is deeply entrenched in STS (Wyatt et al. 2016). ${ }^{7}$ However, this divide is being challenged by the availability of data and a new generation of algorithms that lead to old theoretical questions being revisited.

This chapter contributes to bridging the gap between quantitative and qualitative methods based on an articulation between a scientometric analysis and a five-year investigation of the Synbio community conducted by one of the authors (BR). Our original methodology is presented in a previous publication in a more technical way (Raimbault et al. 2016). Here we focus on the main principles of the study. The qualitative investigation is based on a multi-sited ethnography involving France and the USA (Marcus 1995). The 10-month participant observation at three Synbio centres $^{8}$ was completed by attendance at the relevant scientific conferences and by information from over 130 interviews with scientists, technicians, administrative support staff, policy makers, entrepreneurs, and industry project managers.

Based on claims that emergence is a multi-scalar process, and strategic external relations are crucial, we develop three key methodological considerations.

\subsubsection{Delineation}

Since boundary work in an emerging field is work in progress, delineation of the corpus has received considerable attention. In the case of Synbio, we built an initial core corpus comprising articles extracted from the Thomson Reuters Web of Science scientific publications database between 2000 and 2012. The articles matched the simple query condition: 'Topic $=$ synthetic biology'. Since we assume that authors working in the domain may not use the expression 'synthetic biology' systematically, we decided to perform a lexical expansion (Mogoutov and Kahane 2007) which allowed us to identify 11 supplementary terms specific to the field. Thus, our corpus was 4605 scientific articles related to Synbio (Raimbault et al. 2016). As we argue elsewhere, the descriptive characteristics of this corpus are similar to those outlined in Oldham et al.'s (2012) quantitative analysis. ${ }^{9}$ This strategy is relevant to

\footnotetext{
${ }^{7}$ In the 1980s, bridging the qualitative and quantitative approaches was a core objective of Michel Callon, who developed scientometric analysis based on ANT to map the dynamics of science (Callon et al. 1986).

${ }^{8}$ These are the Center for Integrative Synthetic Biology (Massachussetts Institute of Technology, USA), the Institute of Systems and Synthetic Biology (Genopole, France), and Toulouse White Biotechnology (TWB, France).

${ }^{9}$ Shapira et al. (2017) observe that our search strategy is far more restrictive than that exploited by $\mathrm{Hu}$ and Rousseau (2015).
} 
the premises of field theory according to which the Synbio space is not a construction of the analyst but must correspond to the shared understanding of the actors involved.

\subsubsection{Heterogeneity}

We use original and rigorous approaches based on co-citation and lexical networks to identify a set of epistemic clusters and their relative positions. Citation analysis is a traditional scientometric technique which makes it possible to visualise clusters of related citations as the constituent sub-domains of a given research field (Fig. 4.1). The rationale underlying co-citation analysis is that the structure of the co-citation network indexes the epistemic foundations of the research community which

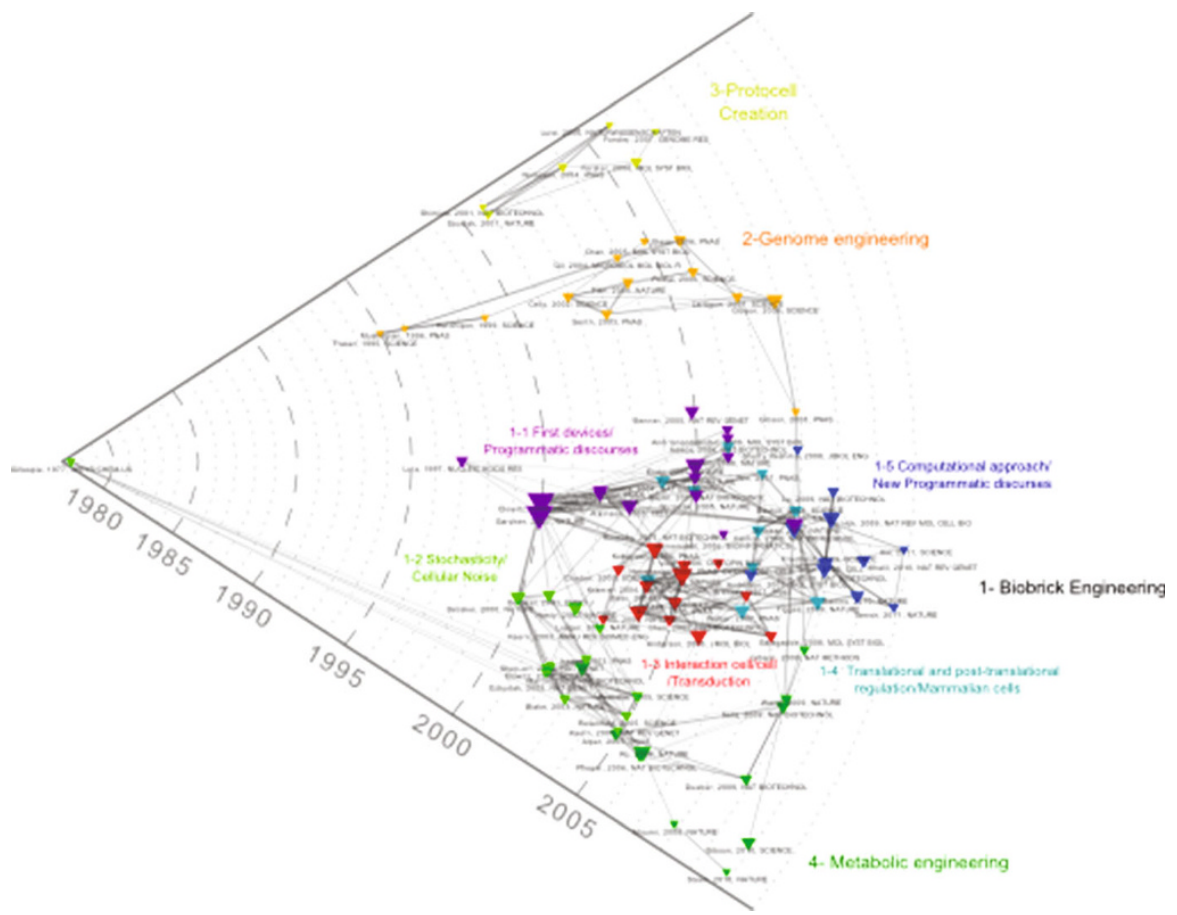

Fig. 4.1 References co-citation map. The 100 most cited references are considered to build a co-citation network. Node sizes scale with the number of citations received by references. Node colour depends on their cluster assignment. Edge widths are proportional to the strength of the link between references. Cluster labels (bold and upper-case) were manually added and correspond to a subfield in Synbio. During this labelling process, we gathered five very tightly connected clusters under the same subfield. We identify four subfields projected on a historical axis, allowing us to follow the dynamic and the weight of each subfield: 1.X DNA-based device construction, 2 Protocell creation, 3 Genome engineering, 4 Metabolic engineering 
consists of groups of seminal works shared by the various sub-communities and not by the prestige or the intentionality of the 'most obvious' authors, ignoring knowledge-production in practice. ${ }^{10}$ Clusters are detected by using an automatic community detection algorithm which determines the multi-level structure of the citation network.

\subsubsection{Distribution of Scientific Capital}

We selected three different indicators to determine the position of each author in the corpus on the assumption that association with those indicators was a good approximation for scientific capital: (1) author centrality (an indicator commonly used in network analysis to measure the extent to which a node is likely to be a passage point for other nodes in a network); (2) cumulative impact of the author's publications in the corpus; and (3) author productivity (number of articles in the corpus). These three indicators are represented on the graph in Fig. 4.3: centrality is represented on the horizontal axis, impact on the vertical axis, and productivity is represented by the size of the circle.

Finally, we completed the formal identification of the core-group, including a set of complementary data related to the building of the socio-economic environment constituting the field. In the STS literature, scientists' attempts to bridge natural and social worlds are central, whereas Bourdieusian field theory is focused more on field purity. In contrast (and according to the frame proposed by Fligstein and McAdam), we are interested in the boundary-spanning dimension of the core-group. Thus, we examine core-group members' involvement in three different sets of activities based on the biographical information of the principal investigator (PI). For each dimension we identify important activities in which the PI either participates or not. The sum of this binary information results in three different scores for each author. The resulting table provides the overall positioning of the members of the core set according to the three indicators (Table 4.1):

(1) their interactions with companies that use new knowledge produced in Synbio and transforms it into new products and processes;

(2) their contribution to the establishment of organisations that contribute to stabilisation of the emergent field;

(3) their contribution to initiatives aimed at building Synbio governance-for example, regulation as well as national and international research programmes. In 2011, Zhang et al. (2011) listed 39 reports produced between 2004 and 2011 dedicated to Synbio governance. This list increases the number of such reports to 58 based on the literature review and our field investigation.

\footnotetext{
${ }^{10}$ In 1974, Collins challenged Crane's questionnaire based methodology, writing that 'there is serious doubt that the most important contributors to the ideas of a scientist are necessarily the most obvious contributors' (Collins 1974, p. 169).
} 
Table 4.1 Repartition of core-group members according their contribution to the Synbio subfields $(\mathrm{BE}=$ Biological Engineering, $\mathrm{ME}=$ Metabolic Engineering, $\mathrm{GE}=$ Genome Engineering and $\mathrm{PC}=$ Protocell Creation) identified previously and their involvement in non-academic activities based on three indicators: Business Development (Bus.), Core-Organisation (Inst.), and Governance (Gov.)

\begin{tabular}{|c|c|c|c|c|c|c|}
\hline $\begin{array}{l}\text { Principal } \\
\text { Investigator }\end{array}$ & Country & Subfield & Institutions & Bus. & Org. & Gov. \\
\hline C. A. Voigt* & USA & $\mathrm{BE}$ & MIT & 3 & 4 & 1 \\
\hline P. Silver* & USA & $\mathrm{BE}$ & Harvard & 2 & 4 & 2 \\
\hline D. Endy* & USA & $\mathrm{BE}$ & Stanford & 3 & 3 & 6 \\
\hline J. Keasling* & USA & BE, ME & Berkeley & 3 & 3 & 2 \\
\hline G. Church* & USA & $\begin{array}{l}\text { BE, ME, } \\
\text { PC }\end{array}$ & Wyss institute & 3 & 3 & 2 \\
\hline J. Collins* & USA & $\mathrm{BE}$ & MIT/Wyss institute & 3 & 2 & 1 \\
\hline R. Weiss* & USA & $\mathrm{BE}$ & MIT & 2 & 2 & 2 \\
\hline A. Arkin* & USA & $\mathrm{BE}$ & Berkeley & 2 & 2 & 0 \\
\hline W. Lim* & USA & $\mathrm{BE}$ & UCSF & 1 & 2 & 1 \\
\hline M. Fussenegger & Switzerland & $\mathrm{BE}$ & ETH Zurich & 3 & 2 & 0 \\
\hline F. Arnold & USA & $\mathrm{BE}$ & Caltech & 3 & 2 & 0 \\
\hline C. Smolke & USA & $\mathrm{BE}$ & Stanford & 3 & 2 & 1 \\
\hline J. Hasty & USA & $\mathrm{BE}$ & UCSD & 2 & 1 & 0 \\
\hline T. Lu & USA & $\mathrm{BE}$ & MIT & 3 & 1 & 0 \\
\hline X. Wang & USA & $\mathrm{BE}$ & Arizona State & 1 & 1 & 0 \\
\hline D. Mcmillen & Canadian & $\mathrm{BE}$ & Toronto & 1 & 1 & 0 \\
\hline W. Weber & Switzerland & $\mathrm{BE}$ & BIOSS (Freiburg) & 3 & 1 & 0 \\
\hline L. You & USA & $\mathrm{BE}$ & Duke & 0 & 1 & 0 \\
\hline G. Stephanopoulos & USA & $\mathrm{BE}$ & MIT & 3 & 1 & 0 \\
\hline T. Segall-Shapiro & USA & BE, GE & MIT & 1 & 0 & 0 \\
\hline J. Liao & USA & $\begin{array}{l}\text { BE, GE, } \\
\text { ME }\end{array}$ & UCLA & 3 & 0 & 0 \\
\hline M. Elowitz & USA & $\mathrm{BE}$ & Caltech & 2 & 0 & 1 \\
\hline S. Benner & USA & $\mathrm{BE}$ & FAME & 3 & 0 & 0 \\
\hline V. De Lorenzo & Spain & $\mathrm{BE}$ & CNB Madrid & 3 & 0 & 2 \\
\hline Y. Zhang & USA & BE, ME & Virginia Tech & 2 & 0 & 0 \\
\hline C. Hutchison & USA & GE & JCVI & 2 & 0 & 0 \\
\hline C. Venter' & USA & GE & JCVI & 3 & 0 & 1 \\
\hline H. Zhao & USA & GE, ME & Illinois University & 2 & 0 & 1 \\
\hline C. Moya & Spain & PC, GE & $\begin{array}{l}\text { University of } \\
\text { Valencia }\end{array}$ & 0 & 0 & 0 \\
\hline
\end{tabular}

The presence of a * indicates the participation of the author in the Synthetic Biology Engineering Research Center (SynBERC) 


\subsection{Mapping the Emergence of Synbio as a Technoscientific Field}

\subsubsection{Heterogeneity}

\section{P1-Heterogeneity (of disciplines, research questions, visions, and social norms) plays a key role in the emergence phase of a new technoscientific field}

As discussed above, we argue that heterogeneity is not only present in but is constitutive of the emergence process. First, subfields are complementary in terms of the formulation of promises and establishment of credibility. Second, heterogeneity is important for addressing the needs of diverse audiences.

Our empirical analysis shows that Synbio does not correspond to a set of research oriented toward a common question. The related research can be better described as a set of distinct research programmes gathered under one umbrella (Rip and Voß 2013). As already mentioned, engineering biology is the central reference bounding the Synbio field and the Synbio community. However, the meanings attached to engineering are diverse, and biologists and social scientists working in Synbio acknowledge this heterogeneity. Frequently, they distinguish among three main approaches: DNA-based construction (another naming convention for a biobrick engineering approach'), genome-driven cell engineering, and protocell creation (O’Malley et al. 2008).

Co-citation analysis allows us to identify four subfields (or research programmes) which are plotted in Fig. 4.1. Three have been identified in previous work (O'Malley et al. 2008) ${ }^{11}$ _biobrick engineering, genome engineering, and protocell creation. The fourth subfield is 'metabolic engineering' which corresponds to a scientific approach established during the late 1990s.

Biobrick engineering is the most central subfield. It uses an explicit electronic metaphor, introduces a set of new concepts such as gene circuits, genetic switches, biobricks, chassis, etc., and refers to modelling. The biobrick approach is the most visionary approach, meaning that its vision for Synbio (programmatic discourses and direction for the field) affects the interpretation of biology (e.g. modularity) or scientific practices (e.g. standardisation). The ambition is to provide a new biology ontology and push for new disruptive practices.

The second subfield, protocell creation, has been diminishing since 2006. Its scope includes basic, even classic, scientific interrogations, such as the origins of life, rather than applications.

Genome engineering tackles two main issues: (1) synthesis of large nucleic acid sequences; and (2) research on a minimal genome. Interestingly, and although Venter is considered a pioneer of Synbio, genome engineering does not connect directly to biobrick engineering.

\footnotetext{
${ }^{11}$ The construction of this typology is actually very different. O'Malley et al.'s classification is based on group intentions and routine practices, whereas ours is based on an automatic process.
} 
Finally, metabolic engineering stands out in the sense that this cluster refers to an existing and already stabilised technoscientific field. Work on this approach is characterised by a strong focus on applications (e.g. production of artemisinin) and optimisation of expression of metabolic pathways.

Rather than seeing this heterogeneity as a weakness in the structuration of Synbio, epistemic diversity is a resource contributing to the stabilisation of the field. Epistemic disruption is promoted by the most promising approach (biobrick engineering), whereas the cohesion between approaches is related to an already established field (metabolic engineering). The biobrick approach provides vanguard visions of the field (Hilgartner 2015). This approach is well-known for its ability to promise and to stimulate utopian discourse, which is efficient for recruiting practitioners and attracting particular policy makers and funders. On the other hand, metabolic engineering (and to a lesser extent genome engineering) provides credibility because of its demonstrated ability to deliver technological applications. Promises allow resources to be mobilised and used to explore new research avenues. At the same time, they put pressure on the scientists and the institutions involved to engage in the design of practical applications.

\subsubsection{Hierarchy}

\section{P2-Alliances between different types of scientific entrepreneurs (incumbents and challengers) are instrumental to the process of emergence}

Our scientometric dataset provides critical information on the evolving population of scientists active in Synbio. From a quantitative perspective, publications and newcomers show high rates of growth (Fig. 4.2). In 2014 (the last year for which the dataset can be considered complete) there were 3044 unique authors, 2133 of whom were newcomers (never previously published in the field). Hence, although decreasing, the proportion of scientists that had published only once in Synbio was above $60 \%$ in 2014. We can assume that an important proportion of those authors who have published once in Synbio would not consider themselves synthetic biologists; they more likely feel a sense of belonging to some other field.

However, over time, the internal connectivity of the field increases sharply. In Fig. 4.2, connectivity is measured by the size of the 'largest component'-defined as the largest subset of researchers connected through a direct path in the collaboration network (green curve in Fig. 4.2). This increase can be interpreted as signalling an intensive process of community-building.

The concomitance of population growth and its connectivity is a sign of maturation. However, it tells us little about the part of the community that considers itself attached to Synbio and which is active in building the field. To identify this subgroup, we applied three measures systematically: network centrality, scientific recognition (impact measured by the number of citations received), and productivity (number of publications in Synbio). We identified a group of 30 individuals with the 


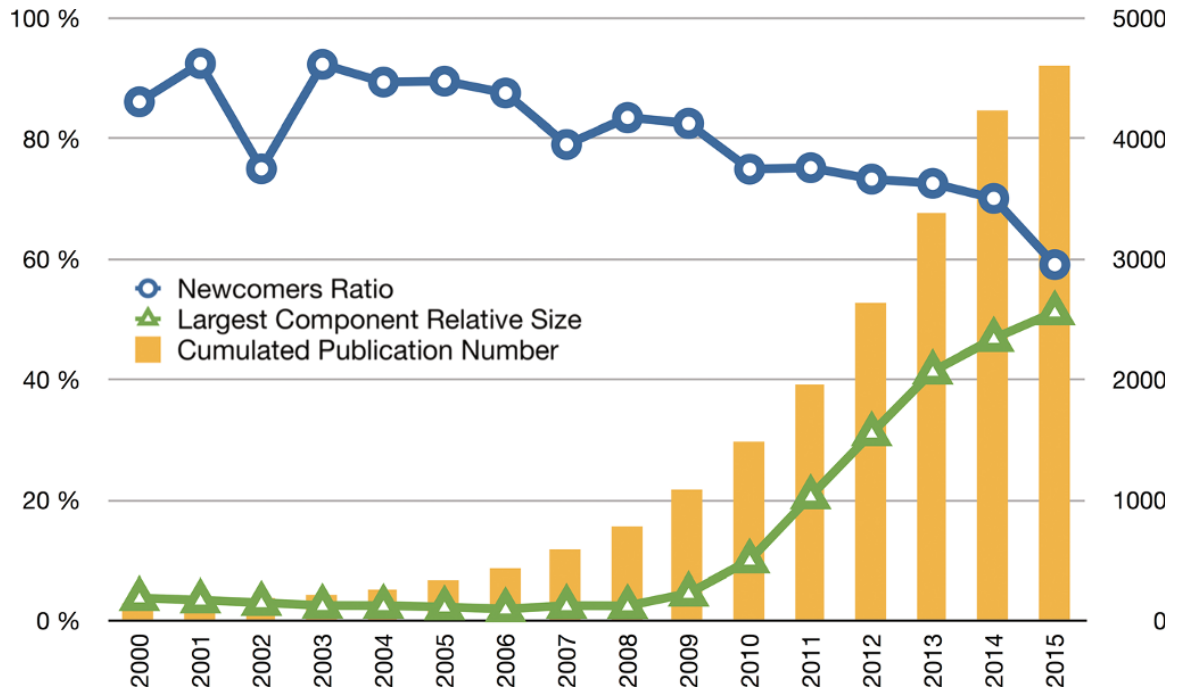

Fig. 4.2 Global population statistics for the synbio community over time. Cumulated number of publications (bar chart), ratio of newcomers, and largest component relative size. While the number of publications follows a typical exponential growth, the newcomers ratio-while very high-is decreasing with time, and the largest component relative size has been growing significantly since 2010 , indicating progressive structuration of the Synbio community

highest global score obtained as the product of author centrality and impact, ${ }^{12}$ allowing us to bridge across field and network effects. We call this collective the core-group.

Figure 4.3 shows how stratified the population is: more than 10,000 scientists (over 11,321 scientists who have published at least once in Synbio) record both very low impact and centrality. They are concentrated in the bottom left corner of Fig. 4.3. The 30 scientists with the highest scores are plotted on a pie diagram showing the distribution of their articles among the four different approaches (green for biobricks engineering, yellow for genome engineering, purple for metabolic engineering, and pink for protocell creation). Four descriptive comments are needed. First, we observe an over-representation of US-based scientists: among the 30 members of the coregroup, 25 work in US institutions. Second, members of the core-group all work in prestigious institutions. Their academic career paths reflect the involvement of these institutions in Synbio. Third, the epistemic landscape is strongly defined by members of this core-group, who are co-authors of 77 of the 100 most cited articles in the corpus. Fourth, members of the core-group are highly concentrated in the central approach of biobrick engineering, which is coherent with our analysis.

\footnotetext{
${ }^{12}$ This product is equivalent also to computation of the product of centrality, average impact per paper, and number of publications.
} 


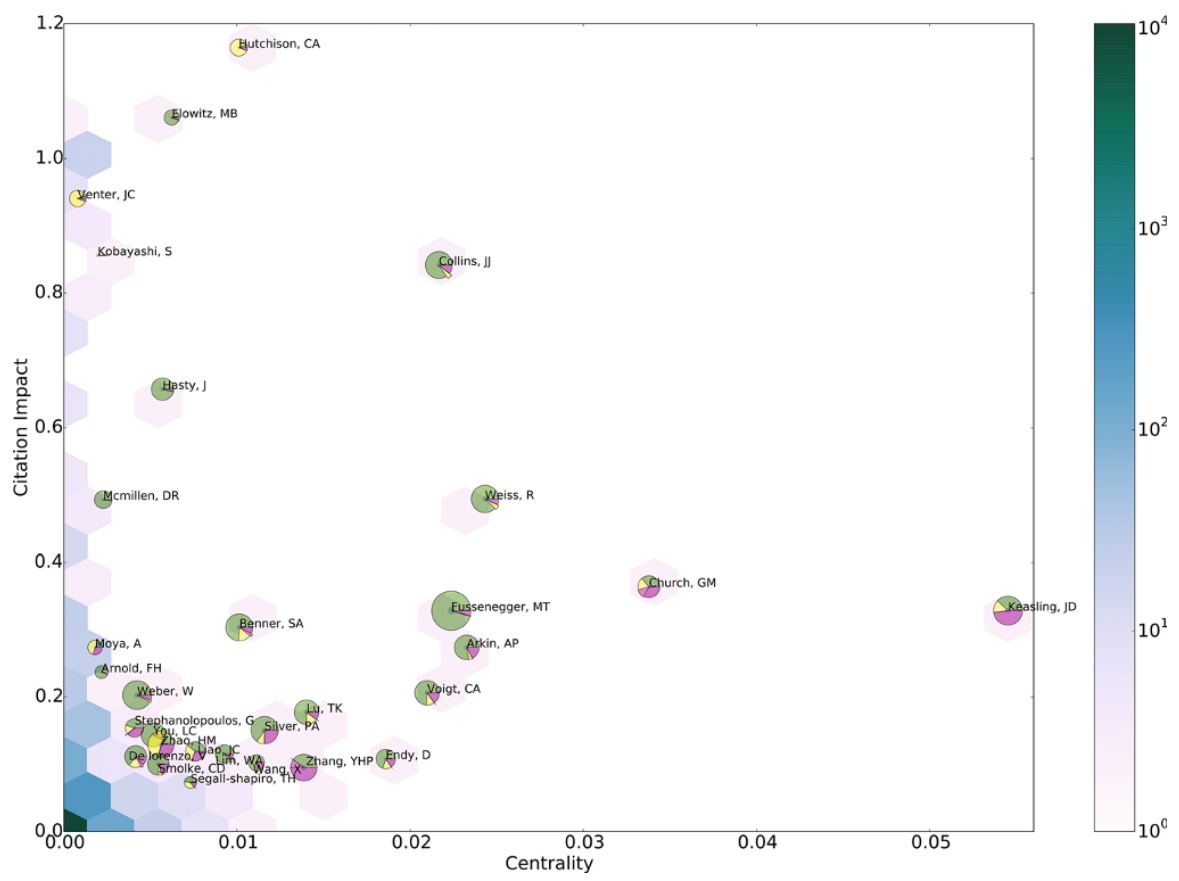

Fig. 4.3 Position analysis of the main actors in the synbio community according to centrality and impact

The composition of capital among the core-group is also heterogeneous. Looking at the network, we see that some scientists may not be central but are highly influential (Venter, Elowitz); some are very central and highly influential (Keasling, Church); others are not very influential but are very central (Endy); etc. This heterogeneity in the composition of capital is important since the core-group is composed of scientists with different skills and positions, both well-established scientists and challengers.

It is important to note that the social skills of core-group members do not consist only of their capacity to formulate attractive research questions. They are also linked closely to community-building. Our indicator 'core-organisations' includes the involvement of core-group members in the main stabilising organisations of Synbio already identified in social science analysis. They are: the iGEM competition (judge, advisor, or laboratory registered by the contest), which is considered 'the most important community-building activity in the biobricks field' (Calvert 2012); the ERC programme SynBERC (PI and affiliated PI); and some international conferences such as SBX.0 (organiser and member of the steering committee) and SEEDSynthetic Biology: Engineering, Evolution, Design (organiser and member of the steering committee).

PIs in the biobrick approach are the most active: 21 out of 25 PIs linked to this approach are involved in at least one of these organisations (Table 4.1). The most 
active PIs in the three organisations (score of 3 or 4) belong to the biobrick approach; adherents to other approaches are comparatively less systematically involved in these kinds of organisations. All those subscribing to the genome engineering approach, for example, have a score of less than or equal to 1. It is interesting that although J. C. Venter is often considered to be one of the founders of the Synbio domain, according to our indicators he is not involved in the construction of the Synbio community (score $=0$ ). Four of six PIs linked to the metabolic engineering approach have scores lower than or equal to 1 . This is a reflection not of lack of involvement in the scientific organisations of Synbio but merely of the fact that in this approach representatives are already invested in specific metabolic engineering organisations. For example, Stephanopoulos, a pioneer in the field, edits Metabolic Engineering and was one of the founders of the international conference cycle 'Metabolic Engineering', whose fourth conference was co-organised by Liao. Finally, the centrality of Jay Keasling can be explained by his strong participation in Synbio organisations (he is director of SynBERC) and metabolic engineering (he was a member of the editorial board of Metabolic Engineering and has participated in many metabolic engineering conferences, etc.).

Although the scientists in the core-group have different profiles, different visions, and different positions in the field, they regularly combine their efforts to promote the field by setting up new projects or devices which support community-building. An emblematic example is the creation of the Synthetic Biology Engineering Research Center (SynBERC), established at Berkeley (Rabinow and Bennett 2012).

Hence, the core-group has a central position and plays a very active role in community-building. Importantly, the alliance strategies of incumbents and outsiders are decisive in this process. Two comments are due here. First, although defined by very formal criteria, this core-group includes the informal networks identified in the literature as at the heart of development of the domain. Second, and contrary to the Synbio literature, our analysis puts Drew Endy's role into perspective. The combination of strategies related to different positions appears to be a crucial element in the emergence process.

\subsubsection{Autonomy}

P3-The importance of the strategies for the control of external resources in the process of emergence

Analysis of the interactions between Synbio and non-scientific areas draws on the core-group identified based on the criteria of centrality and scientific recognition discussed above. Our qualitative analysis shows that these 'star scientists' also play important roles as boundary spanners. We consider the contributions of the members of the core-group to relations with industry and Synbio governance.

First, members of the core-group are heavily involved in activities aimed at realising the commercial potential of Synbio. Since the 1980s, the hybrid nature of 
scientists who are both researchers and entrepreneurs (Shapin 2009) has been emphasised. According to Kleinman and Vallas (2001), this is part of a broader phenomenon of asymmetric convergence related to alignment between the codes and practices of academia and industry. Thus, asymmetry refers to the uneven nature of the circulations between the two social worlds to the benefit of industry. In relation to its effect, particularly on the world of biology, asymmetric convergence has been studied extensively but seldom considered a source of credibility for the establishment of an emerging field. Mackenzie (2013) points out that one of the strategies of synthetic biologists to establish the credibility of the domain consists of building intermediate technical achievements. However, Mackenzie does not consider the commercial character of these technical achievements, whereas we assume it to be central as per the most recent report from the American Academy of Sciences concerning Synbio entitled Industrialization of Biology. ${ }^{13}$ Our indicator 'business development' draws on three kinds of information: participation in a start-up scientific advisory board (SAB), creation of a start-up, and ownership of patents as the inventor. Almost all the PIs (27 out of 29) are involved in the economic sector, and two-thirds of them score high for 'business development'. Almost all PIs (27 out of 29) have applied for a patent as an inventor. This is an exceptionally high score despite the patenting of academic research results becoming routine in biotechnology (Sauermann and Stephan 2012). Finally, 20 members of the core-group are members of at least one SAB, and 17 have created a start-up. This involvement is extremely high for members of the core set who were identified by their centrality in scientific production.

Second, members of the core-group are very active in the setting up of organisations to promote the development of Synbio and build its legitimacy. We consider four criteria: (1) being a PI in the Synthetic Biology Engineering Research Center (SynBERC) ${ }^{14}$ considered the seminal organisation of the field (Rabinow and Bennett 2012; Schyfter and Calvert 2015); (2) being a member of a lab entered in the iGEM contest, which annually gathers thousands of students in Boston (Calvert 2012; Keller 2009) ${ }^{15}$; (3) organisation of one of the International Meetings on Synthetic Biology organised by the Biobrick Foundation (SBX.O) (Campos 2012); and (4) organisation of the annual SEED conference, which has become one of the main events for the international Synbio community following its creation in 2014.

Our 'governance' indicator captures the participation of members of the coregroup in the preparation of reports dedicated to Synbio governance and advocacy for state intervention. The literature highlights the early work related to legitimising Synbio in intensive production of grey literature (Zhang et al. 2011). This work is

\footnotetext{
${ }^{13}$ Industrialization of biology: A roadmap to accelerate the advanced manufacturing of chemicals. (2015). Retrieved from https://www.nap.edu/catalog/19001/industrialization-of-biology-aroadmap-to-accelerate-the-advanced-manufacturing

${ }^{14}$ Between 2015 and 2016, 11 interviews were conducted with the main PIs in SynBERC.

${ }^{15}$ Synthetic Biology Labs Registered. (n.d.). Retrieved from http://igem.org/Lab_List
} 
conducted in multiple spaces: regulatory (final opinion on synthetic biology I, II, $\mathrm{III}^{16}$ ), ethical (Presidential Commission for Bioethical Issues ${ }^{17}$ ), scientific (conferences, iGEM competition, academies of sciences), and industry (report on the regulation of synthetic genes ${ }^{18}$ ). It is common to include the synthetic biologists among the authors of these reports. For instance, to create this indicator we listed 58 reports which reflect the importance of governance issues in Synbio. About half of the core-group (13 PIs) has coordinated at least one report dedicated to one aspect of Synbio governance. This involvement remains relatively targeted since only one of the 13 PIs concerned has been involved in more than two reports. ${ }^{19}$ Governance issues constitute a collective and institutionalised element of discussion on Synbio development and are maturing alongside the scientific and economic environment. The most representative example of the heterogeneous agenda alignment is undoubtedly Drew Endy (author of 6 reports). The profile of activities of J. C. Venter should also be mentioned. Although he was personally involved in only one-albeit decisive-report (by the Presidential Commission for the Study of Bioethical Issues), his J. Craig Venter Institute is very active in governance issues. Indeed, staff in this centre who are trained in law and political science have prepared reports on the regulation of Synbio.

\subsection{Conclusion}

This chapter conceptualises the emergence of a TSF as a multiscalar and progressive establishment of a new set of epistemic and social rules. In order to account for this phenomenon, we draw on STS and field theories to propose an original methodological and conceptual framework which is attentive to the interactions between structure and agency in the analysis of change.

Our conceptual contribution relies on the design of an approach focused on three core propositions for characterising the emergence process of a TSF. We use innovative scientometric tools to create specific variables that allow us to investigate both network and field structural dynamics. Hence, this chapter contributes to the

\footnotetext{
${ }^{16}$ Final Opinion on Synthetic Biology. (2014). https://ec.europa.eu/health/scientific_committees/ consultations/public_consultations/scenihr_consultation_21_en

${ }^{17}$ The Ethics of Synthetic Biology: Guiding Principles for Emerging Technologies. (2011). Retrieved from https://president.upenn.edu/meet-president/ethics-synthetic-biology-guiding-princi ples-emerging-technologies

${ }^{18}$ Synthetic biology and the US biotechnology regulatory system: Challenges and options. (2014). Retrieved from https://www.jcvi.org/sites/default/files/assets/projects/synthetic-biology-and-theus-regulatory-system/full-report.pdf

${ }^{19}$ Note that we used a very discriminating criterion for building our 'governance' indicator because we considered only strong implications in the various reports (e.g. organisation, editing, coordination)
} 
current stream of research that aims to bridge qualitative and quantitative approaches.

We use the emergence of synthetic biology to illustrate this approach and test our methodology. This novel approach could obviously be applied to other emerging fields. Beyond validation aspects, a comparative exercise of diverse emergent TSF would allow classical STS issues to be revisited in relation to what is called 'the new production of knowledge' (Gibbons et al. 1994; Nowotny et al. 2001).

First, a comparative study of different emergent TSF would make possible a more precise investigation of science-industry relations and knowledge production in the context of applications. While the rise of commodification of science is now commonly identified (Mirowski et al. 2008), we still lack studies on the way that it affects research content (Gläser and Laudel 2016) and how industry is a crucial site for the establishment of credibility. The use of scientometrics would facilitate comparison, while strict ethnographic studies are often closely attached to a specific site (Kleinman 2003). This could help to identify various types of commodification and to study how far this is related to the differentiation of contemporary sciences.

Second, the emergence of TSF is also a political process. Our study showed how the involvement of core scientists in realising the commercial potential of the field cannot be dissociated from involvement in governance issues. Here, the collective strategy has been highlighted at a micro level. Comparative studies between emergent TSF engaging political science literature would allow a macro-level strategy to be reached. In particular, it would be interesting to consider the constitution of scientific communities as a site where national science policies and globalised circulation of knowledge articulate or confront each other (Jasanoff 2011).

Finally, comparison does not have to be restrained to emergent TSF. Our framework makes it possible to study scientific production dynamics in line with David Hess' proposition for 'a more deeply historised sociology of scientific knowledge'. (Hess 2006). Synbio is not the first field claiming to engineer biology, and a comparison with the structuration of metabolic engineering - a field already settled in the 1990s-shows how fields are intertwined and combined each other (Raimbault 2018). Heterogeneity is thus also a temporal heterogeneity, and novel fields could be considered as the reformulation of existing practices, concepts, or organisations.

Acknowledgments The authors wish to thank the Laboratoire Interdisciplinaire Science Innovation Société at Université Paris-Est for the research assistance and more especially David Demortain, Marianne Noël, Jean-Philippe Cointet and Catherine Paradeise for discussing previous versions of the chapter. This work also benefited greatly from comments by the two reviewers and the editors. 


\section{References}

Bensaude-Vincent, B. 2013. Discipline-building in synthetic biology. Studies in History and Philosophy of Science Part C: Studies in History and Philosophy of Biological and Biomedical Sciences 44 (2): 122-129.

Berman, E.P. 2014. Field theories and the move toward the market in US academic science. In Fields of knowledge: Science, politics and publics in the neoliberal age, ed. S. Frickel and D.J. Hess, 193-221. Bingley: Emerald Group Publishing Limited.

Bourdieu, P. 1975. La spécificité du champ scientifique et les conditions sociales du progrès de la raison. Sociologie et sociétés 7 (1): 91-118.

Callon, M., J. Law, and A. Rip. 1986. Qualitative scientometrics. In Mapping the dynamics of science and technology, ed. M. Callon et al., 103-123. London: Palgrave Macmillan.

Calvert, J. 2012. Ownership and sharing in synthetic biology: A 'diverse ecology' of the open and the proprietary? BioSocieties 7 (2): 169-187.

Campos, L. 2012. The BioBrick ${ }^{\mathrm{TM}}$ road. BioSocieties 7 (2): 115-139.

. 2013. Outsiders and in-laws: Drew Endy and the case of synthetic biology. In Outsider scientists: Routes to innovation in biology, ed. O. Harman and M.R. Dietrich, 331-348. University of Chicago Press.

Collins, H.M. 1974. The TEA set: Tacit knowledge and scientific networks. Social Studies of Science 4 (2): 165-185.

1981. The place of the 'core-set' in modern science: Social contingency with methodological propriety in science. History of Science 19 (1): 6-19.

Crane, D. 1972. Invisible colleges: Diffusion of knowledge in scientific communities. Chicago: University of Chicago Press.

European Commission. The Scientific Committees on consumer safety, on emerging and newly identified health risks, on health and environmental risks (2014) Final opinion on Synthetic Biology.

Evans, J.A. 2010. Industry collaboration, scientific sharing, and the dissemination of knowledge. Social Studies of Science 40 (5): 757-791.

Fligstein, N., and D. McAdam. 2012. A theory of fields. Oxford/New York/Auckland: Oxford University Press.

Frickel, S. 2004. Building an interdiscipline: Collective action framing and the rise of genetic toxicology. Social Problems 51 (2): 269-287.

Frickel, S., and N. Gross. 2005. A general theory of scientific/intellectual movements. American Sociological Review 70 (2): 204-232.

Frickel, S., and K. Moore. 2006. The new political sociology of science: Institutions, networks, and power. University of Wisconsin Press.

Gibbons, M., C. Limoges, H. Nowotny, S. Schwartzman, P. Scott, and M. Trow. 1994. The new production of knowledge: The dynamics of science and research in contemporary societies. SAGE.

Giddens, A. 1984. The constitution of society: Outline of the theory of structuration. University of California Press.

Gieryn, T.F. 1995. Boundaries of science. In Science and the quest for reality, ed. A.I. Tauber, 293-332. London: Palgrave Macmillan.

Gläser, J., and G. Laudel. 2016. Governing science: How science policy shapes research content. European Journal of Sociology/Archives Européennes de sociologie 57 (1): 117-168.

Granovetter, M.S. 1973. The strength of weak ties. American Journal of Sociology 78 (6): $1360-1380$.

Hackett, E.J., J.N. Parker, N. Vermeulen, and B. Penders. 2016. The social and epistemic organization of scientific work. In The handbook of science and technology studies, ed. U. Felt, R. Fouché, C.A. Miller, and L. Smith-Doerr, 4th ed., 733-765. Cambridge, MA: MIT Press.

Hess, D.J. 2006. Antiangiogenesis research and the dynamics of scientific fields: Historical and institutional perspectives in the sociology of science. In The new political sociology of science: 
Institutions, networks, and power, ed. S. Frickel and K. Moore, 122-148. University of Wisconsin Press.

Hilgartner, S. 2015. Vanguards, visions and the synthetic biology revolution. In Science and democracy: Making knowledge and making power in the biosciences and beyond, ed. S. Hilgartner, C. Miller, and R. Hagendijk, 33-56. Routledge.

$\mathrm{Hu}, \mathrm{X}$., and R. Rousseau. 2015. From a word to a world: The current situation in the interdisciplinary field of synthetic biology. PeerJ 3: e728.

Jasanoff, S. 2011. Designs on nature: Science and democracy in Europe and the United States. Princeton University Press.

Joly, P.-B. 2013. On the economics of techno-scientific promises. In Débordements: Mélanges Offerts à Michel Callon, ed. M. Akrich, Y. Barthe, F. Muniesa, and P. Mustar, 203-222. Presses des Mines via OpenEdition.

Joly, P.-B., and V. Mangematin. 1996. Profile of public laboratories, industrial partnerships and organization of R \& D: The dynamics of industrial relationships in a large research organization. Research Policy 25 (6): 901-922.

Keller, E.F. 2009. What does synthetic biology have to do with biology? BioSocieties 4 (2-3): 291-302.

Kleinman, D.L. 2003. Impure cultures: University biology and the world of commerce. University of Wisconsin Press.

Kleinman, D.L., and S.P. Vallas. 2001. Science, capitalism, and the rise of the 'knowledge worker': The changing structure of knowledge production in the United States. Theory and Society 30 (4): 451-492.

Knorr-Cetina, K. 1999. Epistemic cultures: How the sciences make knowledge. Harvard University Press.

Kuhn, T.S. 1962. The structure of scientific revolutions. Chicago: University of Chicago Press.

Latour, B., and S. Woolgar. 1986. Laboratory life: The construction of scientific facts. Princeton University Press.

Lemaine, G., R. Macleod, M. Mulkay, and P. Weingart. 2012. Perspectives on the emergence of scientific disciplines. Walter de Gruyter.

Mackenzie, A. 2013. Realizing the promise of biotechnology: Infrastructural-icons in synthetic biology. Futures 48: 5-12.

Marcovich, A., and T. Shinn. 2011. Where is disciplinarity going? Meeting on the borderland. Social Science Information 50 (3-4): 582-606.

Marcus, G. 1995. Ethnography in/of the world system: The emergence of multi-sited ethnography. Annual Review of Anthropology 24: 95-117.

Mirowski, P., E.-M. Sent, E.J. Hackett, O. Amsterdamska, M. Lynch, and J. Wajcman. 2008. The commercialization of science and the response of STS. In Handbook of science and technology studies, ed. E.J. Hackett, O. Amsterdamska, and M. Lynch, 635-689. Cambridge, MA: MIT Press.

Mogoutov, A., and B. Kahane. 2007. Data search strategy for science and technology emergence: A scalable and evolutionary query for nanotechnology tracking. Research Policy 36 (6): 893-903.

Molyneux-Hodgson, S., and M. Meyer. 2009. Tales of emergence-Synthetic biology as a scientific community in the making. BioSocieties 4 (2-3): 129-145.

Mullins, N.C. 1972. The development of a scientific specialty: The Phage Group and the origins of molecular biology. Minerva 10 (1): 51-82.

Nowotny, H., P. Scott, and M. Gibbons. 2001. Re-thinking science: Knowledge and the public in an age of uncertainty. London: Polity Press.

O’Malley, M.A., A. Powell, J.F. Davies, and J. Calvert. 2008. Knowledge-making distinctions in synthetic biology. BioEssays 30 (1): 57-65.

Oldham, P., S. Hall, and G. Burton. 2012. Synthetic biology: Mapping the scientific landscape. PLoS One 7 (4): e34368.

Rabinow, P., and G. Bennett. 2012. Designing human practices: An experiment with synthetic biology. University of Chicago Press. 
Raimbault B. 2018. A l'ombre des biotechnologies: Reformuler la production de savoirs par la bio-ingénierie en France et aux Etats-Unis. PhD dissertation, Université Paris-Est Marne la Vallée.

Raimbault, B., J.-P. Cointet, and P.-B. Joly. 2016. Mapping the emergence of synthetic biology. PLoS One 11 (9): e 0161522.

Rip, A., and J.-P. Voß. 2013. Umbrella terms as mediators in the governance of emerging science and technology.

Sauermann, H., and P. Stephan. 2012. Conflicting logics? A multidimensional view of industrial and academic science. Organization Science 24 (3): 889-909.

Schyfter, P., and J. Calvert. 2015. Intentions, expectations and institutions: Engineering the future of synthetic biology in the USA and the UK. Science as Culture 24 (4): 359-383.

Shapin, S. 2009. The scientific life: A moral history of a late modern vocation. University of Chicago Press.

Shapira, P., S. Kwon, and J. Youtie. 2017. Tracking the emergence of synthetic biology. Scientometrics 112 (3): 1439-1469.

Wyatt, S., S. Milojević, H.W. Park, and L. Leydesdorff. 2016. The intellectual and practical contributions of scientometrics to STS. In The handbook of science and technology studies, ed. U. Felt, R. Fouché, C.A. Miller, and L. Smith-Doerr, 4th ed., 87-113. Cambridge, MA: MIT Press.

Zhang, J., C. Marris, and N. Rose. 2011. The transnational governance of synthetic biology: Scientific uncertainty, cross-borderness and the 'art' of governance, Report no. 4. London: City, University of London. Retrieved from http://openaccess.city.ac.uk/16098/1/Transnational \%20Governance\%20SynBio\%202011.pdf.

Open Access This chapter is licensed under the terms of the Creative Commons Attribution 4.0 International License (http://creativecommons.org/licenses/by/4.0/), which permits use, sharing, adaptation, distribution and reproduction in any medium or format, as long as you give appropriate credit to the original author(s) and the source, provide a link to the Creative Commons license and indicate if changes were made.

The images or other third party material in this chapter are included in the chapter's Creative Commons license, unless indicated otherwise in a credit line to the material. If material is not included in the chapter's Creative Commons license and your intended use is not permitted by statutory regulation or exceeds the permitted use, you will need to obtain permission directly from the copyright holder.

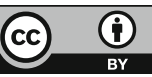

